\title{
Optimizing And Comparative of Polymer-45S5BG and Polymer- HA Coating by Electrophoretic Deposition (EPD)
}

\author{
Nour Abdulkareem Rasheed*, Makarim H. Abdulkareem and Iman Adnan Anoon \\ Department of Production and Metallurgy Engineering, University of Technology, Baghdad - Iraq
}

\section{ARTICLE INFO.}

Article history:

Received: 7 November 2021

Accepted: 2 December 2021

Keywords:

Electrophoretic deposition

Gelatin

Chitosan

45S5BG

Taguchi approach

\begin{abstract}
In this study, two systems of bio-ceramic coating (45S5 bioactive glass and hydroxyapatite) were used in order to compare between them for biomedical applications. Each system consists from two layers of coating done by electrophoretic deposition (EPD) technique on 316L stainless steel material as substrate. Two types of biopolymers were used (Chitosan with Gelatin) as first layer of coating. Taguchi approach with L9 array was used in order to choose the best conditions (concentrations, voltage and time) for coating layers. Each system consists of two-layer (biopolymer (first layer) and bioceramic (second layer)) materials. The optimum parameters for first layer of biopolymer were ( $3 \mathrm{~g} / \mathrm{L}$ concentration, 20 voltage and 3 minute) while optimum parameters for second layer of bioceramic group $(6 \mathrm{~g} / \mathrm{L}$ concentration, 30 voltage and 1 minute) for $45 \mathrm{~S} 5 \mathrm{BG}$ system and (6g/L concentration, 40 voltage and 1 minute) for HA system. Zeta potential test were employed to measure suspensions stability. The tape test method was used to evaluate the adhesion between substrate and coating layers, the results show that the percentage of removal area for optimum coating layer (biopolymer, 45S5 BG and HA $8.06 \%, 10.668 \%, 6.01 \%$ subsequently). XRD inspection was used for identify the phases of coating layers. The Cyclic polarization test was used for evaluation of pitting corrosion resistance, the results show all layers gives good corrosion resistance but 45S5BG system gives the best corrosion resistance when compared with HA system.
\end{abstract}

\section{Introduction}

During the last a few decades the demand for artificial implants has dramatically increased $[1,2]$. Metallic materials are often used to replace structural components of the human body. In general, metallic implant when contact with body environment always prone to corrosion and this led to damage surrounding tissue due to release toxic ions and poor adhesion of metals with living tissue because of metals and its alloy not bioactive $[3,4]$. Austenitic stainless steel is the type of medical grade $316 \mathrm{~L}$ stainless steel was used for implant fabrication in orthopedic applications because its good mechanical properties, high tensile strength and proper density for load bearing purposes in addition to its good chemical and biological properties with low cost compared with others metal implants[5,6]. Metallic implants (316L stainless steel) will treated in way improved their bioactivity and osseointegration [7]. Practical solution has been applied, it was coating 316L stainless steel substrate by bio-ceramics materials for improve its biological and antimicrobial properties [8]. Natural polymer incorporation to bio-ceramic materials also led to improve osseointegration

\footnotetext{
* Corresponding author.

E-mail address: noorkareem772@yahoo.com

DOI: $10.24237 /$ djes.2021.14402
} 
[9]. There are three types of surface bioactive ceramics (Hydroxyapatite and related calcium phosphates, bioactive glasses and glassceramics) [10].The bio ceramic coatings protecting the metallic implants and orthopedic /dental devices from corrosion when in contact with body fluids. Chitosan is natural cationic polymer is always used for biomedical applications due to non-toxic, biodegradable, biocompatible, hemostatic, hydrophobicity, antibacterial activity, its structure allows specific modifications without too many difficulties. But chitosan have disadvantage involve for bone formation require long time, cross linkers needed to maintain the integrity of structure [11]. Gelatin has advantage which biodegradable, biocompatible, very low antigenicity, good cell recognition and disadvantage involve fast degradation rate in physiological fluids and brittle [12]. While, Gelatin use as composite coating in biomedical application with chitosan for improve biocompatibility like cell adhesion and proliferation due to good affinity of cell to gelatin. In general, there is variety of techniques for biomedical coating; Electrophoretic deposition (EPD) is a versatile, simple, rapid method for the processing of ceramics, polymers and their combinations. EPD is a colloidal processing technique, which combines electrophoresis and deposition, where charged, colloidal particles from a stable suspension are deposited onto an oppositely charged substrate by the application of electric field and deposition refers to the coagulation of particles on the substrate $[13,17]$.
Makarim et al [18] studied HA with chitosan on SS316L by EPD with Taguchi approach, Iman et al [19] studied the effect of HA with chitosan on $316 \mathrm{~L}$ SS substrate coated by EPD method on pitting corrosion resistance. Rehman et al [20] studied coating SS316L substrate by EPD with chitosan, gelatin and copper doped bioactive glass (Cu-BG) composite coatings, S.Heise et al [21] used Chitosan-Gelatin for coating 316L SS by EPD method.

The aim of this study is combination between gelatin and chitosan as first layer on 316L stainless steel substrate to control on degradation rate, improve biocompatibility, decrease ion release, adhesion with substrate as first layer and as separating layer between layer and second layer will be mixing of bio-ceramic (Bioglass ${ }^{\circledR}$ (45S5) or HA) suspension with chitosan suspension. Then comparison between the two systems of bio-ceramic group: bioactive glass system and Hydroxyapatite system

\section{Experimental procedure \\ 2.1 material}

1. $316 \mathrm{~L}$ stainless steel used as substrate has the chemical composition listed in table1. The chemical analysis for this substrate was carried out using optical emission spectrometer (OES) type (Foundry-Master x pert 52Q0080) available in the Central Organization for Standardization and Quality Control in Baghdad-Iraq.

Table 1: Chemical compositions analysis of 316L stainless steel

\begin{tabular}{ccccccccccccc}
\hline Elements wt\% & $\boldsymbol{C}$ & $\boldsymbol{S i}$ & $\boldsymbol{M n}$ & $\boldsymbol{P}$ & $\boldsymbol{S}$ & $\boldsymbol{C r}$ & $\boldsymbol{M o}$ & $\boldsymbol{A l}$ & $\boldsymbol{N i}$ & $\boldsymbol{C o}$ & $\boldsymbol{C u}$ & $\boldsymbol{N b}$ \\
\hline wt\% & 0.015 & 0.578 & 1.35 & 0.043 & 0.008 & 16.8 & 1.79 & 0.003 & 9.35 & 0.221 & 0.244 & 0.005 \\
Elements & $\mathrm{Ti}$ & $\mathrm{V}$ & $\mathrm{W}$ & $\mathrm{Ta}$ & $\mathrm{N}$ & $\mathrm{Sn}$ & $\mathrm{Pb}$ & $\mathrm{Se}$ & $\mathrm{Sb}$ & others & $\mathrm{Fe}$ & $\mathrm{F}$ \\
$\mathrm{Wt} \%$ & 0.011 & 0.039 & 0.037 & $>0.01$ & 0.041 & 0.011 & 0.003 & 0.003 & $>0.003$ & $>0.001$ & remain & \\
\hline
\end{tabular}

2. Two types of polymers were used ((Gelatin type B purchased from $\mathrm{CDH}$, and Chitosan (medium molecular weight with a degree of deacetylation of about $85 \%$ soluble in $1 \%$ acetic acid) (purchased from Sigma Aldrich)).
3. Bio-ceramic (Bio-glass ${ }^{\circledR}(45 \mathrm{~S} 5)$ ) powder with nominal composition: $45 \quad \mathrm{SiO}_{2}$ $24.5 \mathrm{Na}_{2} \mathrm{O}-24.5 \mathrm{CaO}-6 \mathrm{P}_{2} \mathrm{O}_{5}$ (wt. \%) with average particle size $65 \mathrm{~nm}$, purity 99.9 , supplied from (Nano research element) and 
(Hydroxyapatite less than 40nm purchased from Sky spring Nanomaterial's, USA).

4. (Deionized water, solvents of ethanol absolute $(99.9 \%)$, Acetic acid with purity $(99.5 \%))$.

\subsection{Sample preparation}

In this work two groups of Sand blast samples prepared, Stainless steel $316 \mathrm{~L}$ electrode plates were cut into dimension $(20 * 10 * 2 \mathrm{~mm})$ and into $(20 * 20 * 2 \mathrm{~mm})$ for corrosion, then ultrasonically cleaned with ethanol and then with acetone for 1 hour then dried immediately before the electrophoretic coating process. The two-electrode coating cell was composed of stainless-steel anode and cathode with $1 \mathrm{~cm}$ distance, an electric voltage was applied by DC power supply.

\subsection{Solution preparation for first layer of gelatin-chitosan}

The important step in the experimental procedure of EPD is preparing the aqueous suspensions. In order to prepare the suspension of gelatin - chitosan composite for EPD, gelatin and chitosan suspensions were prepared separately then mixed. First, $0.5 \mathrm{~g} / \mathrm{L}$ chitosan was dissolved in 1 Vol. \% acetic acid by magnetic stirrer. Then, ethanol was added to the chitosan solution and the suspension stay at stirring. Separately, different concentration of gelatin used as shown in Taguchi approach table 2 gelatin powder was added to 40 Vol. \% deionized water and 1Vol. \% Acetic acid. The dissolution was achieved by magnetic stirring at $50{ }^{\circ} \mathrm{C}$ for 1 hour, based on initial experiments the proper temperature was determined. Hot plate stirrer (MS300HS, MS200) was used. Afterward, the suspension was gently cooled down to room temperature under magnetic stirring. Finally, 59 Vol. \% ethanol was added (after many initial experiments for determine proper percentage of water and ethanol) to gelatin solution they suspension stay at stirring for 1 hour. The prepared chitosan and gelatin solution mixed at stirring for 2 hours, then the suspension was mixed ultrasonically (Ultrasonic Processor, MIXSONIX Incorporated N.Y, USA) for 30 minutes to dispersion of the solid particles.

Table 2: Selected factors and their levels for first layer of biopolymer

\begin{tabular}{cccc}
\hline Factor & \multicolumn{3}{c}{ Level } \\
\hline Concentration of gelatin $(\mathrm{g} / \mathrm{L})$ & 1 & 3 & 5 \\
Time (min) & 1 & 2 & 3 \\
Voltage $(\mathrm{V})$ & 20 & 30 & 40 \\
\hline
\end{tabular}

\subsection{Solution preparation for second layer of bio-} ceramic (Bio-glass ${ }^{\circledR}$ (45S5) and hydroxyapatite) 2.4.1 Solution preparation of second layer (first group (45S5 bioactive glass))

Different concentration of Bio-glass ${ }^{\circledR}$ (45S5) powder was use based on initial experiments for determine the best concentration of BG (45S5) powder to obtain uniform second layer. BG (45S5) suspensions prepared by dissolving different concentration of BG (45S5) powder in deionized water and ethanol by magnetic stirring. $0.5 \mathrm{~g} / \mathrm{L}$ chitosan was dissolved in $1 \mathrm{Vol}$. \% acetic acid by magnetic stirrer. The suspension of Chitosan and 45S5 BG mixed and stays on magnetic stirrer. The suspension of 45S5 BG and Chitosan were ultrasonically for 30 minutes to dispersion of the solid particles. Then, the second layer was deposited. The different concentration of BG (45S5) selected in Taguchi approach shown in Table 3.

Table 3: Selected factors and their levels for second layer of 45S5 BG

\begin{tabular}{cccc}
\hline Factor & \multicolumn{3}{c}{ Level } \\
\hline Concentration of 45S5 BG $(\mathrm{g} / \mathrm{L})$ & 6 & 8 & 10 \\
Time (min) & 1 & 3 & 5 \\
Voltage (V) & 30 & 40 & 50 \\
\hline
\end{tabular}




\subsubsection{Solution preparation for second layer (second group (Hydroxyapatite))}

Different concentration of HA powder was used based on initial experiments for determine the best concentration of HA powder to obtain uniform second layer. HA suspensions prepared by dissolving different concentration of HA powder in deionized water and ethanol by magnetic stirring. $0.5 \mathrm{~g} / \mathrm{L}$ chitosan was dissolved in 1 Vol. \% acetic acid by magnetic stirrer. The suspension of Chitosan and HA mixed and stays on magnetic stirrer. The suspension of HA and Chitosan were ultrasonically for 30 minutes to dispersion of the solid particles. Then, the second layer was deposited. The different concentration of HA selected in Taguchi approach shown in Table 4.

Table 4: Selected factors and their levels for second layer of HA

\begin{tabular}{lccc}
\hline \multicolumn{1}{c}{ Factor } & \multicolumn{3}{c}{ Level } \\
\hline HA Concentration $(\mathrm{g} / \mathrm{L})$ & 6 & 8 & 10 \\
Time (min) & 1 & 3 & 5 \\
Voltage $(\mathrm{V})$ & 30 & 40 & 50 \\
\hline
\end{tabular}

\subsection{EPD of first layer (chitosan-gelatin} suspension) and second layer for two groups (bioceramic suspension)

316L stainless steel sheet were cut into predefined dimension. This sheet employed as substrate. The electrode (anode and cathode) cleaned with ethanol and distance between the electrode was kept constant at $10 \mathrm{~mm}$. EPD for first layer (chitosan-gelatin suspension) was performed at voltage of $(20,30$ and 40$) \mathrm{V}$ for various time periods of $(1,2$, and 3$)$ min as shown in Table 2. While the second layer which involves two group systems: first group of bio-glass (chitosan- BG (45S5)) suspension and second group of hydroxyapatites (chitosan- HA) suspension as second layer was performed at (30, 40 , and 50) $\mathrm{V}$ for various time periods of $(1,3$, and 5) min as shown in table 3 and table 4 .

\subsection{Taguchi design of experiments (DOE)}

The selection of control factor is the most important step in DOE. To reduce the number of experiments and optimize the EPD parameters, the design of experiment approach with Taguchi methodology was applied. In this research the control factor was (concentration, applied voltage and deposition time) of first layer of biopolymer and second layer of two group for bio-ceramic shown in table 2,3 , and 4 .

\section{Results and discussions}

3.1. EPD of chitosan-gelatin by using (DOE approach)

For optimize the EPD parameter the Taguchi DoE approach was used. Table 5 list the removal area\% of (chitosan-gelatin) layers obtained from Taguchi design of experiments. There was a wide range of removal area\% for coating layers produce as different level of variables. According to the SNs ratio theory (smaller is the better) for removal area\% (Table 5). It can be seen from Table 5 that samples 6 have the lowest values of coating remove. The corresponding optimum levels for this experiment are $3 \mathrm{~g} / \mathrm{L}$ concentrations, 20Voltage and $3 \mathrm{~min}$ time (experiment 6). Measurements of the solution stability for these optimum levels were obtained by zeta potential for gelatin- chitosan suspension; it was $(77.38 \mathrm{mV})$. There is a good dispersion of particles in the solution as shown in Fig. 1. Zeta potential of gelatin particles in deionized water and zeta potential of gelatin in chitosan suspension was measured. Negative zeta potential was exhibited by pure gelatin in deionized water was $(-26.81$ $\mathrm{mV}$ ), while gelatin suspension with chitosan suspension shows positive zeta potential, so cathodic EPD coating deposition was achieved. $\mathrm{pH}$ meter with acetic acid was used to adjustment range of $\mathrm{pH}$ value of solutions by using (pH-ECTDS Meter Portugal). The $\mathrm{pH}$ of gelatin-chitosan suspension was (4.8). 


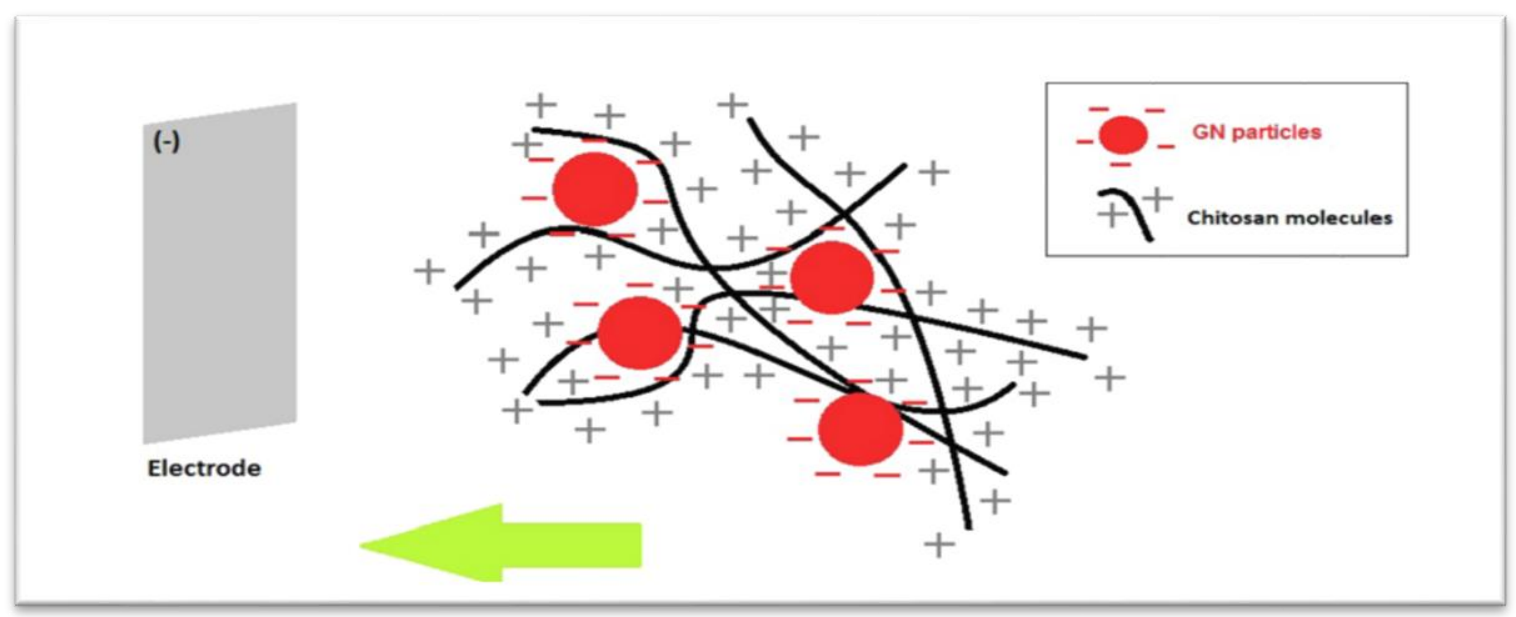

Figure 1. Proposed EPD deposition mechanism of gelatin particles in a chitosan suspension [22,23]

Table 5 and Fig 2 show the SNs ratio for removal area \% of first layer of biopolymer for all variables at different level. Table 6 explains the ranking of significance of each level in various responses which derived from SNs data. It was noticed that the concentration has the highest effect on this procedure. The time has the second effect, while lowest effect was voltage. The analysis of variance (ANOVA) shows that the first layer removal area\% is highly controlled by concentration rather than the time and voltage. Contribution for concentration was (81.47\%) (Table 7).

Table 5: Removal area $\%$ and SNs ratio for all experiments for first layer

\begin{tabular}{ccccccc}
\hline No & Concentration(g/L) & Time(min) & Voltage(V) & Removal area $\%$ & SNRA & MEAN \\
\hline 1 & 1 & 1 & 20 & 12.34 & -21.8263 & 12.34 \\
2 & 1 & 2 & 30 & 13.25 & -22.4443 & 13.25 \\
3 & 1 & 3 & 40 & 15.15 & -23.6083 & 15.15 \\
4 & 3 & 1 & 30 & 17.09 & -24.6548 & 17.09 \\
5 & 3 & 2 & 40 & 13.26 & -22.4509 & 13.26 \\
6 & 3 & 3 & 20 & 8.06 & -18.1267 & 8.06 \\
7 & 5 & 1 & 40 & 25.35 & -28.0796 & 25.35 \\
8 & 5 & 2 & 20 & 35.08 & -30.9012 & 35.08 \\
9 & 5 & 3 & 30 & 43.44 & -32.7578 & 43.44 \\
\hline
\end{tabular}

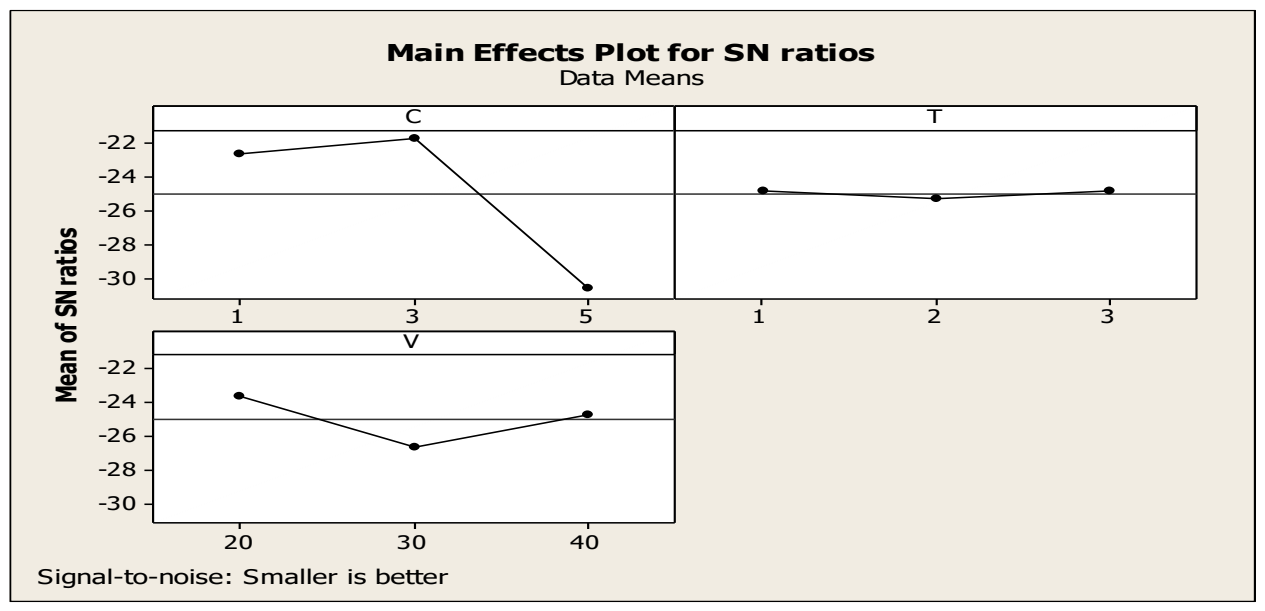

Figure 2. Mean of SNs response for first layer removal area\% for different variables and levels 
Table 6: Rank for variables of first layer removal area\% and process performance for each level

\begin{tabular}{cccc}
\hline Level & Concentration & Time (min) & Voltage(v) \\
\hline 1 & -23.67 & -22.48 & -22.10 \\
2 & -20.69 & -23.20 & -23.94 \\
3 & -25.05 & -23.73 & -23.36 \\
Delta & 4.36 & 1.25 & 1.84 \\
Rank & 1 & 3 & 2 \\
\hline
\end{tabular}

Table 7: Analysis of variance (ANOVA) for removal area\% for first layer of biopolymer

\begin{tabular}{cccc}
\hline Source of variance & DOF & Squares Sum & Contribution (\%) \\
\hline C & 2 & 919.5 & $81.47 \%$ \\
Time & 2 & 24 & $2.10 \%$ \\
V & 2 & 82 & $7.27 \%$ \\
Error,(e) & 2 & & \\
Total & 9 & 1128.7 & 100 \\
\hline
\end{tabular}

\subsection{EPD of chitosan- bioactiveglass (45S5) by using (DOE approach)}

For optimize the EPD parameter the Taguchi DOE approach was used. Table 8 list the removal area\% of (chitosan- 45S5 BG) second layers (first group of bio-ceramic) obtained from Taguchi design of experiments. There was a wide range of removal area\% of second layer of first group of bioceramic produce as different level of variables. According to the SNs ratio theory (smaller is the better) (Table 8 ). It can be seen from Table 8 that samples 1 have the lowest values of coating remove. The corresponding optimum levels for this experiment are $6 \mathrm{~g} / \mathrm{L}$ of $45 \mathrm{~S} 5 \mathrm{BG}$ concentration, $1 \mathrm{~min}$ and $30 \mathrm{~V}$ (experiment 1). Measurements of the solution stability for these optimum levels were obtained by zeta potential. There is a good dispersion of particles in the solution. 45S5 BG particles in water and in chitosan suspension was measure zeta potential for it. Negative zeta potential was exhibited by pure $45 \mathrm{~S} 5 \mathrm{BG}$ in water it was $(-91.61 \mathrm{mV})$, while in chitosan suspension show positive zeta potential so cathodic deposition achieved it was $(96.93 \mathrm{mV})$. The PH for suspension was less than (5). Table 8 and Fig 3 show the SNs ratio for removal area\% of second layer of bio-ceramic (first group) for all variables at different level. Table 9 explains the ranking of significance of each level in various responses which derived from SNs data. It was noticed that the concentration has the highest effect on this procedure. The time has the second effect, while lowest effect was voltage. The analysis of variance (ANOVA) shows that the first layer adhesion is highly controlled by concentration rather than the time and voltage (Table 10). The concentration contribution was $(34.98 \%)$

Table 8: Removal area\% and SNs ratio for all experiments for second layer (first group)

\begin{tabular}{lcccccc}
\hline No & Concentration(g/L) & Time(min) & Voltage(V) & Removal area $\%$ & SNRA & MEAN \\
\hline 1 & 6 & 1 & 30 & 10.668 & -20.5617 & 10.668 \\
2 & 6 & 3 & 40 & 30.276 & -29.6220 & 30.276 \\
3 & 6 & 5 & 50 & 38.978 & -31.8164 & 38.978 \\
4 & 8 & 1 & 40 & 42.000 & -32.4650 & 42.000 \\
5 & 8 & 3 & 50 & 35.994 & -31.1246 & 35.994 \\
6 & 8 & 5 & 30 & 37.904 & -31.5737 & 37.904 \\
7 & 10 & 1 & 50 & 30.929 & -29.8073 & 30.929 \\
8 & 10 & 3 & 30 & 40.365 & -32.1201 & 40.365 \\
9 & 10 & 5 & 40 & 55.062 & -34.8170 & 55.062 \\
\hline
\end{tabular}




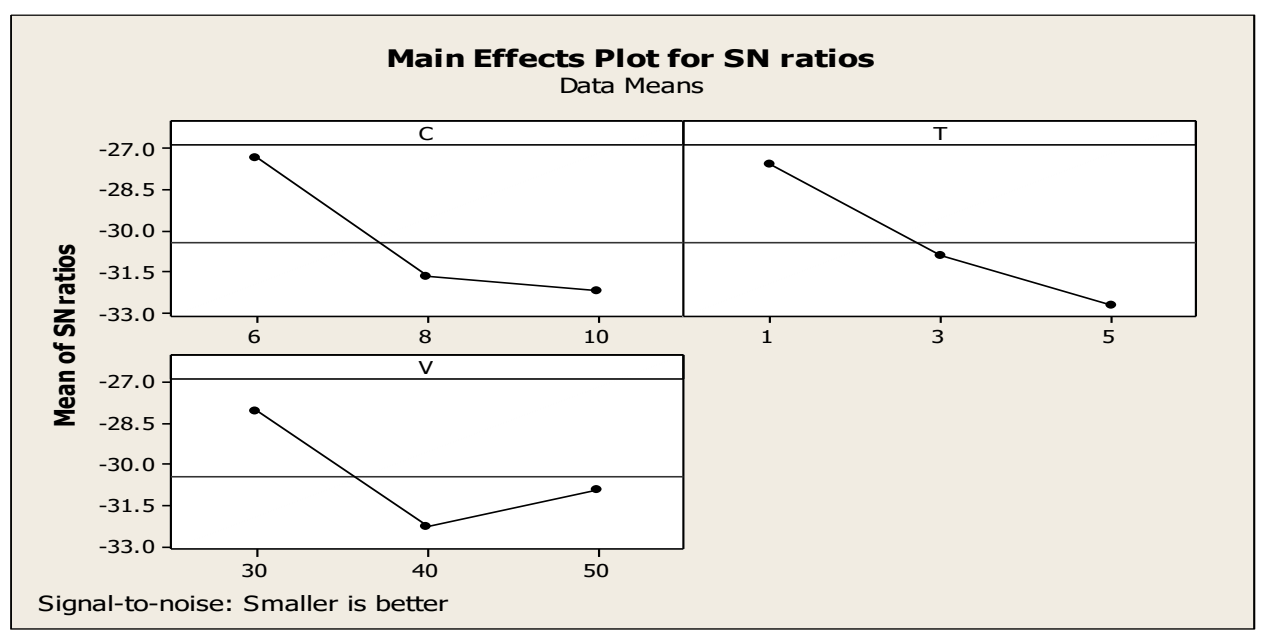

Figure 3. Mean of SNs response removal area\% for different variables and levels for bio-ceramic (45S5 BG group)

Table 9: Rank for variables of bio-ceramic (first group) removal area\% and process performance for each level

\begin{tabular}{cccc}
\hline Level & Concentration & Time (min) & Voltage(v) \\
\hline 1 & -27.33 & -27.61 & -28.09 \\
2 & -31.72 & -30.96 & -32.30 \\
3 & -32.25 & -32.74 & -30.92 \\
Delta & 4.91 & 5.12 & 4.22 \\
Rank & 2 & 1 & 3 \\
\hline
\end{tabular}

Table 10: Analysis of variance (ANOVA) for the of bio-ceramic (first group) removal area\%.

\begin{tabular}{cccc}
\hline Source of variance & DOF & Squares Sum & Contribution (\%) \\
\hline C & 2 & 396 & $34.98 \%$ \\
Time & 2 & 390 & $34.48 \%$ \\
V & 2 & 247 & $21.83 \%$ \\
Error ,(e) & 2 & & \\
Total & 8 & 1131 & 100 \\
\hline
\end{tabular}

\subsection{EPD of chitosan -HA by using (DOE approach)}

For optimize the EPD parameter the Taguchi approach was used. Table 11 list the removal area\% of (chitosan- HA) second layers (second group) obtained from Taguchi design of experiments. There was a wide range of removal area\% produce as different level of variables. According to the SNs ratio theory (smaller is the better). It can be seen from Figure 4 the optimum parameters are $6 \mathrm{~g} / \mathrm{L}$ of HA concentration, $1 \mathrm{~min}$ and $40 \mathrm{~V}$ and the removal area for this experiment is $6.01 \%$ as shown (fig7a). This experiment near from experiment 1 in Table (11). Measurements of the solution stability for these optimum levels were obtained by zeta potential $(28.71 \mathrm{mV})$. There is a good dispersion of particles in the solution. The PH for suspension was (4.9). Table 11 and Fig 4 show the SNs ratio for removal area\% of second layer of bio-ceramic (second group) for all variables at different level. Table 12 explains the ranking of significance of each level in various responses which derived from SNs data. It was noticed that the concentration has the highest effect on this procedure. The time has the second effect, while lowest effect was voltage. The analysis of variance (ANOVA) shows that the first layer removal area\% is highly controlled by concentration rather than the time and voltage (Table 13). The contribution of concentration was $(88.23 \%)$. 
Table 11: Removal area\% and SNs ratio for all experiments for second layer (second group)

\begin{tabular}{ccccccc}
\hline No & Concentration(g/L) & Time(min) & Voltage(V) & Removal area & SNRA & MEAN \\
\hline 1 & 6 & 1 & 30 & 6.23 & -15.8898 & 6.23 \\
2 & 6 & 3 & 40 & 7.38 & -17.3611 & 7.38 \\
3 & 6 & 5 & 50 & 17.73 & -24.9742 & 17.73 \\
4 & 8 & 1 & 40 & 10.6 & -20.5061 & 10.60 \\
5 & 8 & 3 & 50 & 29.23 & -29.3166 & 29.23 \\
6 & 8 & 5 & 30 & 28.58 & -29.1212 & 28.58 \\
7 & 10 & 1 & 50 & 59.33 & -35.4655 & 59.33 \\
8 & 10 & 3 & 30 & 63.36 & -36.0363 & 63.36 \\
9 & 10 & 5 & 40 & 88.43 & -38.9320 & 88.43 \\
\hline
\end{tabular}

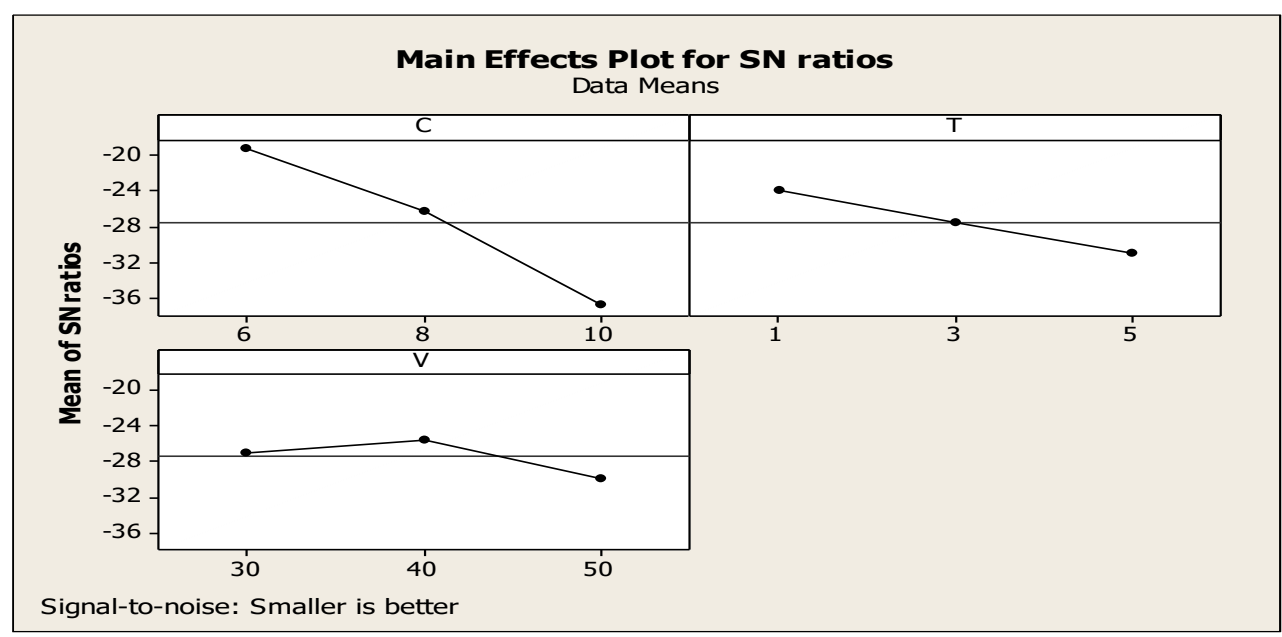

Figure 4. Mean of SNs response removal area\% for different variables and levels for bio-ceramic (HA group)

Table12: Rank for variables of bio-ceramic (second group) removal area\% and process performance for each level

\begin{tabular}{cccc}
\hline Level & Concentration & Time $(\mathbf{m i n})$ & Voltage $(\mathbf{V})$ \\
\hline 1 & -19.41 & -23.95 & -27.02 \\
2 & -26.31 & -27.57 & -25.60 \\
3 & -36.81 & -31.01 & -29.92 \\
Delta & 17.40 & 7.06 & 4.32 \\
Rank & 1 & 2 & 3 \\
\hline
\end{tabular}

Table 13: Analysis of variance (ANOVA) for bio-ceramic (second group) removal area\%

\begin{tabular}{|c|c|c|c|}
\hline Source of variance & DOF & Squares Sum & Contribution (\%) \\
\hline C & 2 & 6007 & $88.23 \%$ \\
\hline Time & 2 & 579 & $8.50 \%$ \\
\hline V & 2 & 15 & $0.22 \%$ \\
\hline Error ,(e) & 2 & & 100 \\
\hline Total & 8 & 6808 & \\
\hline
\end{tabular}

\subsection{Adhesion strength}

This test was done to evaluate the quality of coating layers, so it was important to investigate the strength adhesion of these layers. Therefore, the method of tape test was used for this purpose. It was according to ASTM "D 3359-B" standard. The tape test was performed on nine samples of 
the three system first layer (chitosan-gelatin), first group of second layer (chitosan- 45S5), second group of second layer (chitosan -HA) coatings in order to assess (qualitatively) the adhesion between the coating and the substrate for (first layer (chitosan-gelatin)) and between first layer and second layer of bioceramic group ((chitosan45S5BG), (chitosan- HA)) coating. The results show most of specimens have good strength adhesion for both layers (first layer of biopolymer and second layer of bioceramic group for $45 \mathrm{~S} 5 \mathrm{BG}$ and HA) system as appear values of adhesion test in table 5 for first layer of biopolymer and table $(8,11)$ for two group of bioceramic. It was noticed that the concentration has the highest effect on this procedure for two layers, that give good indication when concentration for gelatin in first layer was $5 \mathrm{~g} / \mathrm{L}$ the last three experiments $(7,8$, and 9) in table 5 gives high percentage of removal coating and this case also for second group of bioceramic for both group when concentration of bioceramic (45S5BG and HA) system was $10 \mathrm{~g} / \mathrm{L}$ also percentage of removal coating for last experiment (9) in both table 8 and 11 was high. As shown in figure 5 that sample 6 of concentration of $3 \mathrm{~g} / \mathrm{L}$ gives more less removal coating than sample 9 of $5 \mathrm{~g} / \mathrm{L}$ concentration for first layer of biopolymer. Also, in second layer for both bioceramic group system when concentration $6 \mathrm{~g} / \mathrm{L}$, gives good adhesion strength and less removel area than sample 9 of concentration $10 \mathrm{~g} / \mathrm{L}$ as shown in Figure 6 and 7.

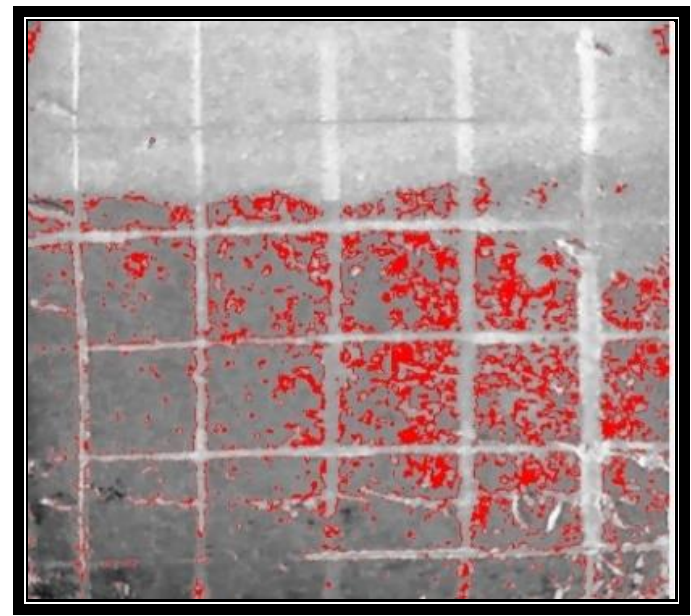

6. $(20 \mathrm{~V}, 3 \mathrm{~min}, 3 \mathrm{~g} / \mathrm{L})$

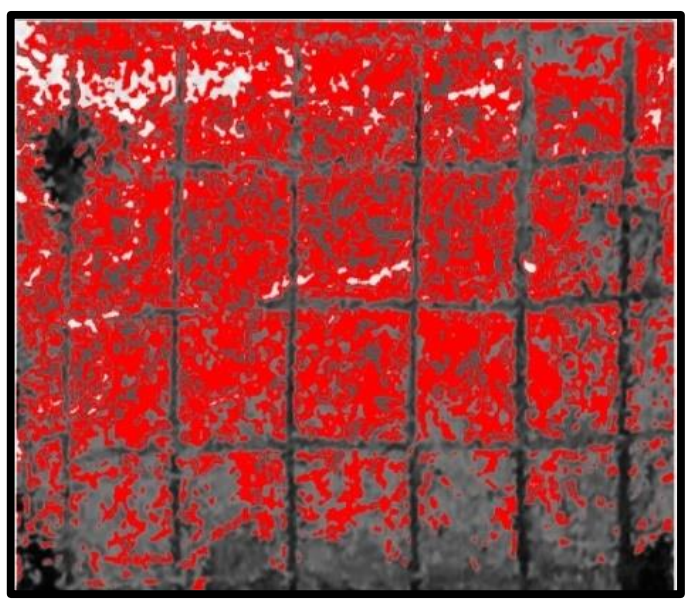

9. $(30 \mathrm{~V}, 3 \mathrm{~min}, 5 \mathrm{~g} / \mathrm{L})$

Figure 5. Optical images of removal area $\%$ for first layer (gelaten- chitosan)

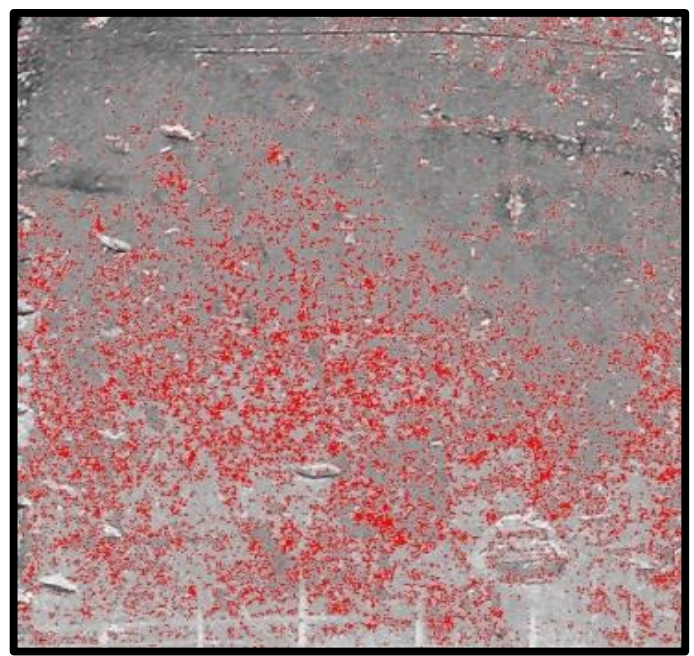

$(30 \mathrm{~V}, 1 \mathrm{~min}, 6 \mathrm{~g} / \mathrm{L})$

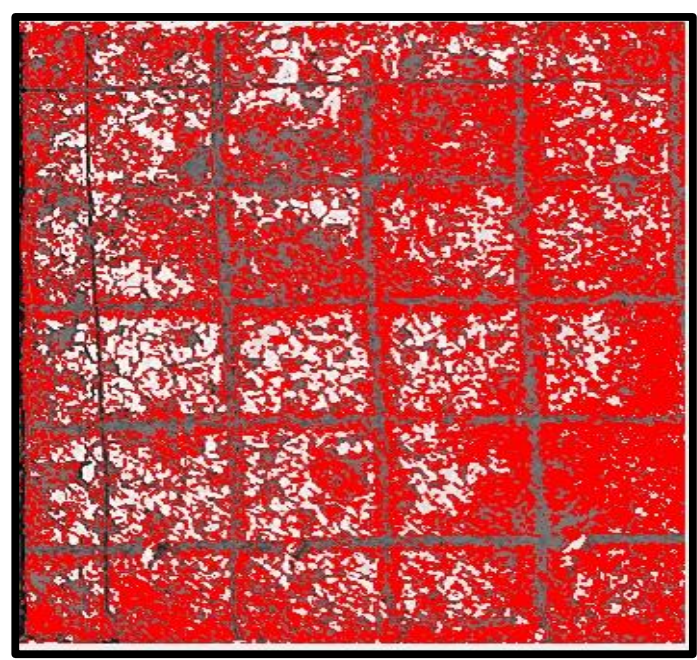

9. $(40 \mathrm{~V}, 5 \mathrm{~min}, 10 \mathrm{~g} / \mathrm{L})$

Figure 6. Optical images of removal area\% for second layers (first group (45S5)) 


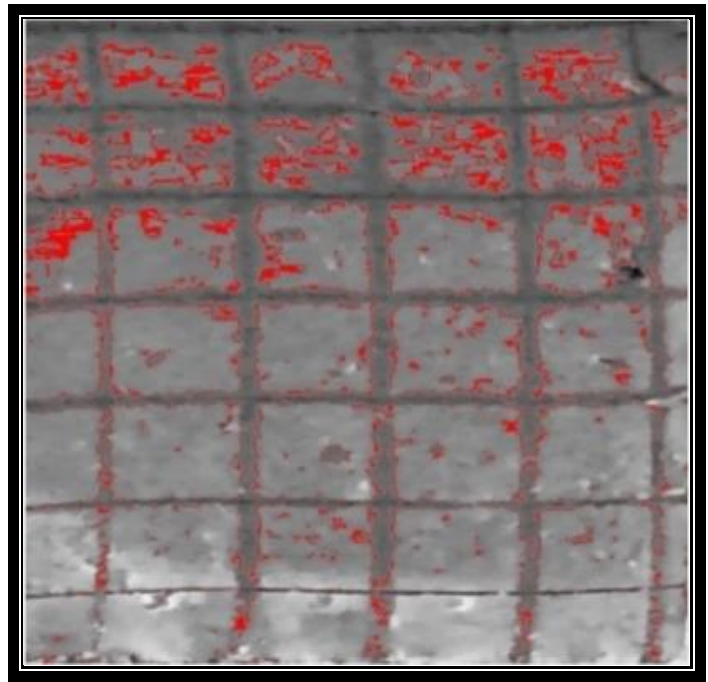

a. $(40 \mathrm{~V}, 1 \mathrm{~min}, 6 \mathrm{~g} / \mathrm{L})$

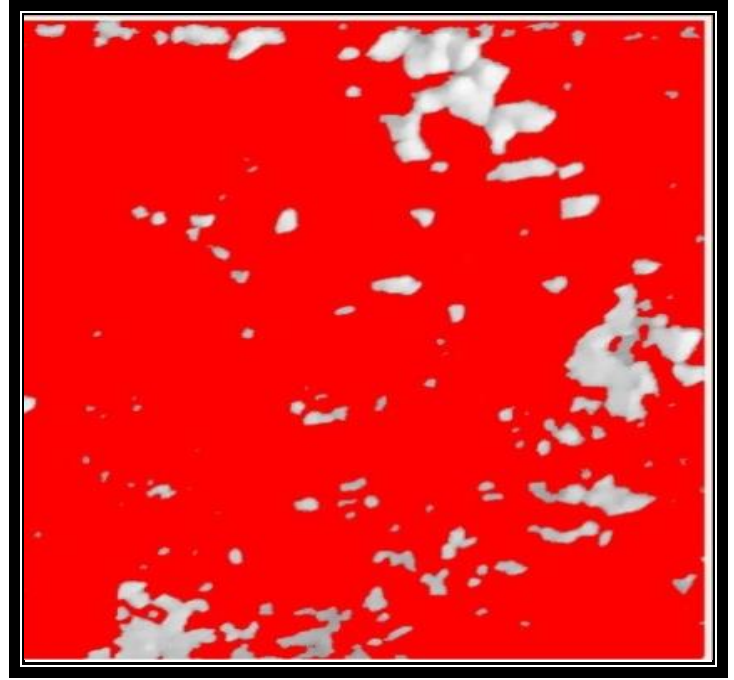

9. $(40 \mathrm{~V}, 5 \mathrm{~min}, 10 \mathrm{~g} / \mathrm{L})$

Figure 7.Optical images of removal area\% for second layers (second group (HA))

\subsection{Structural results}

The X-ray diffraction analysis inspection was used to show the phases identification AISI 316L stainless steel alloy before EPD and after EPD coating. the X-ray diffraction analysis was used to confirmed of the phases for the first layer of biopolymer which consist from (gelatin-chitosan) and second layer of bioceramic for two groups
(BG (45S5) and (HA)). Three different $2 \Theta$ peaks are related for austenitic $316 \mathrm{~L}$ stainless steel $\left[74.76^{\circ}(220), 50.84^{\circ}(200)\right.$ and $\left.43.76^{\circ}(111)\right]$ as shown in figure 8 (A), They identified according to JCPDS card No 33-0397. The XRD pattern is given in Fig. 8(B), clearly demonstrating an amorphous structure with only a broad peak at 2 $\theta=20-30^{\circ}$.

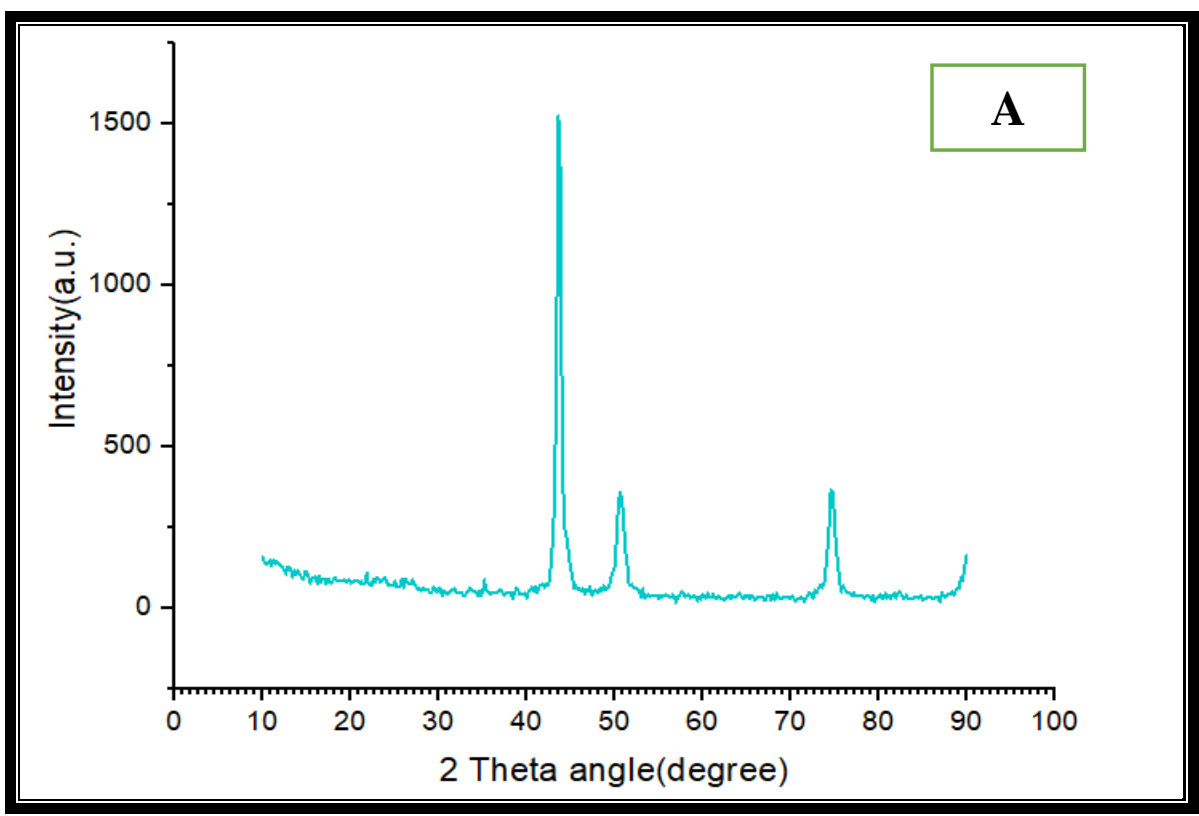




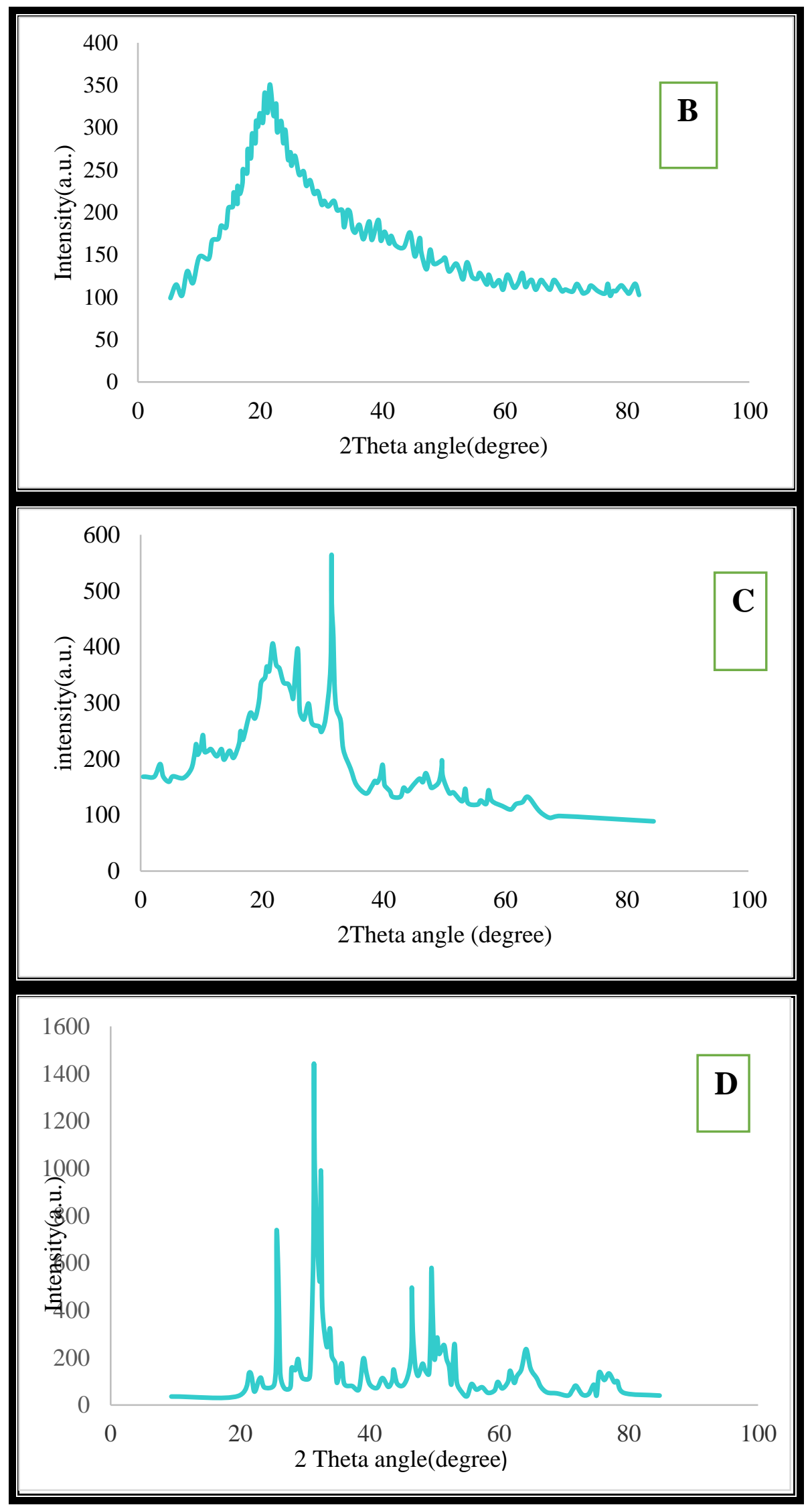

Figure 8. Show XRD pattern for A) 316LSS without coating, B) first layer of (gel.+CH.), C) second layer of first group and D) second layer of second group 


\subsection{Potentiodynamic polarization studies}

The potentiodynamic polarization curve of uncoated (316LSS substrate) and coated sample which involve (first layer of gelatin+chitosan and second layer of bioceramic group) achivied in surrounding condition of laboratory as shown in figure 9. According to value of corrosion potential it was observed that the corossion potential of coated group higher than that of the uncoated sample. This results the first layer and second layer of bioceramic group showed aconsiderable shiffting in corrosion potential that led to decreasing corossion rate. The group of bioceramic (45S5BG) gives high protection than group of (HA).

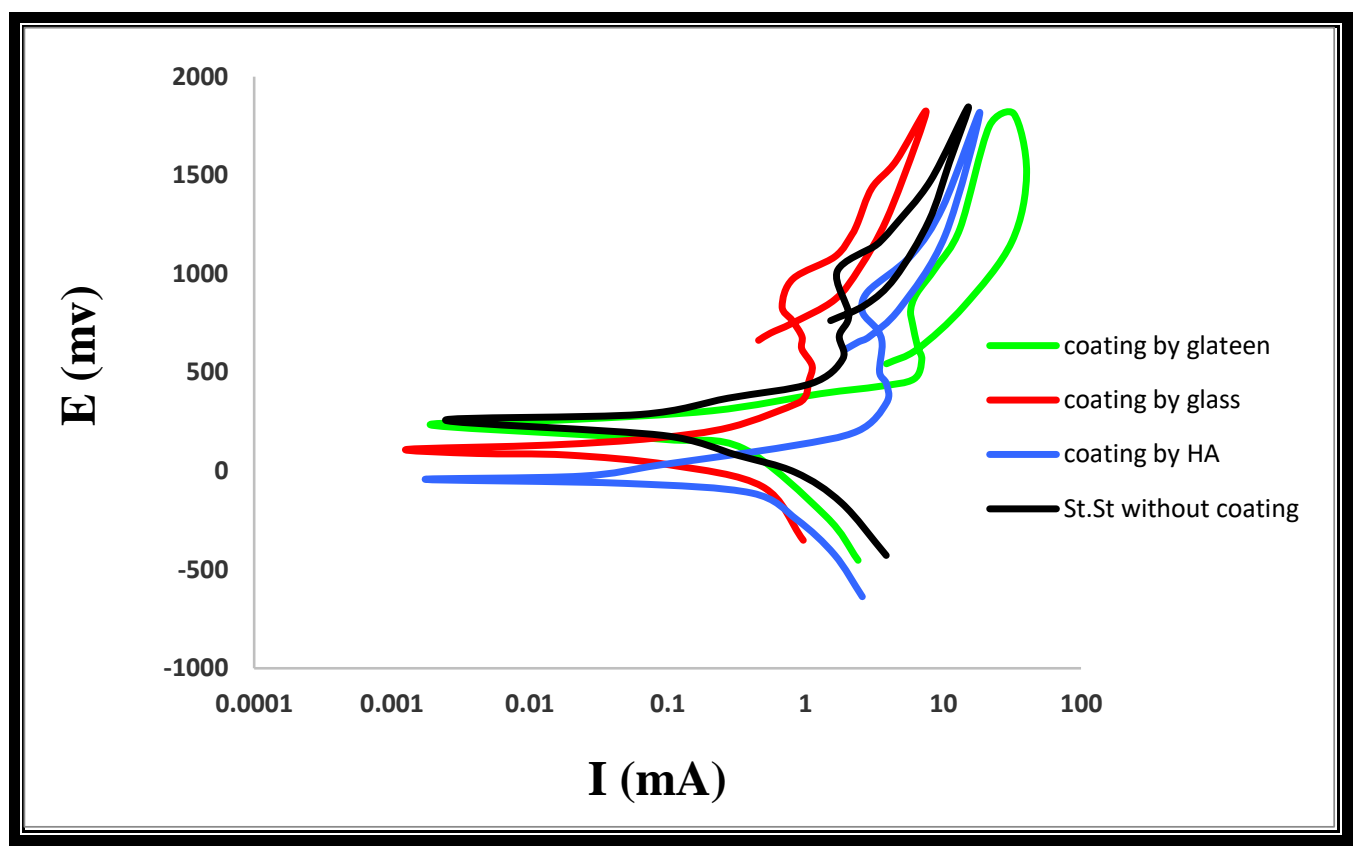

Figure 9. Potentiodynamic polarisation curves for coated bio-composite layers compared to uncoated 316L SS in Ringer solution

\section{Conclusions}

1- The water percentage in EPD suspension for first layer (biopolymer (gelatin-chitosan)) have stronger effect on hemogenity and adhesion coating.

2- The best conditions obtained for first layer of (Chitason-gelatain) was at $20 \mathrm{~V}, 3 \mathrm{~min}$, $3 \mathrm{~g} / \mathrm{L}$ at $50^{\circ} \mathrm{C}$.

3- The best conditions obtained for second layer of bioceramic group 45S5 BG system are $(6 \mathrm{~g} / \mathrm{L}, 1 \mathrm{~min}$ and $30 \mathrm{~V})$ and for HA system $(6 \mathrm{~g} / \mathrm{L}$ concentration, $1 \mathrm{~min}$ and $40 \mathrm{~V})$.

4- Zeta potential for all suspensions suitable value.

5- The adhesion strength for two systems of bioceramic was suitable ( $10.668 \%$ for $45 \mathrm{~S} 5$ BG and $6.01 \%$ for HA system).
6- XRD analysis proved that EPD method didn't affect for changing phases of materials that used in coating. This is related directly to the absence of sintering step and the procedure was done at room temperature.

7- The first group of bioceramic (45S5BG) gives high protection against corrosion as compare second group of bioceramic (HA).

\section{References}

[1] G.W. Hastings. Journal of Physics E-Scientific Instruments. 1980; 13:599.

[2] S.M. Kurtz, E. Lau, K. Ong, K. Zhao, M. Kelly, KJ. Bozic. Clin Orthop Relat Res. 2009; 467:2606.

[3] M.A. Mcgee, D.W. Howie, K. Costi, D.R. Haynes, C.I. Wildenauer, M.J. Pearcy, J.K. Mclean, Wear 241 (2000) 158. 
[4] D.W. Hoeppner, V. Chandrasekaran, Wear 173 (1994) 189

[5] T.M. Sridhar, "Nanobioceramic coatings for biomedical applications", Materials Technology, 25(2010)184-195.

[6] T. Fu, C.S. Wen, J. Lub, Y.M. Zhou, S.G. Mac, B.H. Dong, B.G. Liu, "Sol-gel derived TiO2 coating on plasma nitrided $316 \mathrm{~L}$ stainless steel", Vacuum, 86(2012)1402-1407.

[7] Y. Ramaswamy, C.T. Wu, H. Zreiqat, Expert Rev. Med. Devic 6 (2009) 423

[8] N. Eliaz, T.M. Sridha, U.K. Mudali, B. Raj, "Electrochemical and electrophoretic deposition of hydroxyapatite for orthopaedic applications", Surf. Eng. 21 (2005) 1-5.

[9] D. Bellucci, A. Sola, P. Gentile, G. Ciardelli, V. Cannillo, "Biomimetic coating on bioactive glassderived scaffolds mimicking bone tissue", J. Biomed. Mater. Res. - Part A. 100 A (2012) 32593266.

[10] B. Ben-Nissan, C. Chai, and L. Evans, "Crystallographic and spectroscopic characterization and morphology of biogenic and synthetic Apatites", in Encyclopedic Handbook of Biomaterials and Bioengineering Vol. 1, Part B: Applications, eds. D. L. Wise, D. J. Trantolo, D. E. Altobelli, M. J. Yaszemski, J. D. Gresser, and E.R. Schwartz, (Marcel Dekker Inc., New York, 1995) pp:191-221.

[11] Rinaudo, M. Chitin and chitosan: Properties and applications. Prog. Polym. Sci. 2006, 31, 603-632. [CrossRef]

[12] Kumbar, S.; Laurencin, C.; Deng, M. "Natural and Synthetic Biomedical Polymers"; Elsevier: Berlin/Heidelberg, Germany, 2014; pp. 1-402.

[13] I. Corni, MP. Ryan, A. R. Boccaccini. Journal of the European Ceramic Society. 2008; 28:1353.

[14] L. Besra, M. Liu, A review on fundamentals and applications of electrophoretic deposition (EPD), Prog. Mater. Sci. 52 (2007) 1-61.

[15] A.R. Boccaccini, S. Keim, R. Ma, Y. Li, I. Zhitomirsky, "Electrophoretic deposition of biomaterials"., J. R. Soc. Interface. 7 Suppl 5 (2010) S581-S613.

[16] B. Ferrari, R. Moreno, EPD kinetics: A review, J. Eur. Ceram. Soc. 30 (2010) 1069-1078.

[17] P. Sarkar, P.S. Nicholson, "Electrophoretic Deposition (EPD): Mechanisms, Kinetics and Application to Ceramics”, J. Am. Ceram. Soc. 79 (1996) 1987-2002.

[18] M. J. Kadhim, N. E. Abdullatef, M.H. Abdulkareem, "Optimization of Nano
Hydroxyapatite/chitosan Electrophoretic Deposition on 316L Stainless Steel Using Taguchi Design of Experiments", Al-Nahrain Journal for Engineering Sciences (NJES) Vol.20 No.5, 2017 pp.1215-1227.

[19] Iman.A.Annon, "Advance coating on 316L Stainless steel substrate using an EPD for biomedical application", phd Thesis, university of technology,2016.

[20] M. A. U. Rehman, M. A. Munawar, D. W. Schubert, A. R. Boccaccini, "Electrophoretic deposition of chitosan/gelatin/bioactive glass composite coatings on 316L stainless steel: A design of experiment study", Sct (2018).

[21] S. Heise, C. Forster, S. Heer, H. Qi, J. Zhou, S. Virtanen, T. Lu, A. R. Boccaccini, "Electrophoretic deposition of gelatine nanoparticle/chitosan coatings", Electrochimica Acta 307(2019), 318325 .

[22] E. Avcu, F.E. Bas, tan, H.Z. Abdullah, M.A.U. Rehman, Y.Y. Avcu, A.R. Boccaccini, "Electrophoretic deposition of chitosan-based composite coatings for biomedical applications": a review, Prog. Mater. Sci. 103 (2019) 69e108.

[23] S. Heise, M. Hohlinger, Y.T. Hernandez, J.J.P. Palacio, J.A. Rodriquez Ortiz, V. Wagener, S. Virtanen, A.R. Boccaccini, "Electrophoretic deposition and characterization of chitosan/bioactive glass composite coatings on $\mathrm{Mg}$ alloy substrates, Electrochim". Acta 232 (2017) $456 \mathrm{e} 464$. 